\title{
Joint Nordic nuclear research to strengthen nuclear emergency preparedness after the
} Fukushima accident

\author{
Andersson, Kasper Grann; Linde, Christian; Magnússon, Sigurður M.; Physant, Finn
}

Published in:

Journal of Environmental Radioactivity

Link to article, DOI:

10.1016/j.jenvrad.2018.07.023

Publication date:

2018

Document Version

Peer reviewed version

Link back to DTU Orbit

Citation (APA):

Andersson, K. G., Linde, C., Magnússon, S. M., \& Physant, F. (2018). Joint Nordic nuclear research to strengthen nuclear emergency preparedness after the Fukushima accident. Journal of Environmental Radioactivity, 192, 440-447. https://doi.org/10.1016/j.jenvrad.2018.07.023

\section{General rights}

Copyright and moral rights for the publications made accessible in the public portal are retained by the authors and/or other copyright owners and it is a condition of accessing publications that users recognise and abide by the legal requirements associated with these rights.

- Users may download and print one copy of any publication from the public portal for the purpose of private study or research.

- You may not further distribute the material or use it for any profit-making activity or commercial gain

- You may freely distribute the URL identifying the publication in the public portal 


\title{
Joint Nordic nuclear research to strengthen nuclear emergency preparedness after the Fukushima accident
}

\begin{abstract}
Contrary to most areas of Europe, the Nordic countries (Denmark, Finland, Iceland, Norway, Sweden, and the Faroe Islands) have for many years shared a regional research and development program on nuclear reactor safety and emergency preparedness - NKS. In spite of its project results having received great recognition and having been integrated in state-of-the-art emergency preparedness tools over the world, NKS as an organization does not seem well known outside the Nordic countries. Although the Fukushima accident had no health impact at all in Nordic areas, it taught a number of lessons of generic nature with respect to new R\&D tasks that could further strengthen and secure future maintenance of the Nordic region's capability to effectively respond to such events. For broader inspiration, this paper briefly introduces the Nordic nuclear emergency preparedness cooperation channels and outlines the related NKS R\&D project initiatives launched after the Fukushima accident, many of which should be of general interest also far outside the region. The paper is intended as an introduction to NKS with an invitation to explore its results. All project results are available cost-free on the NKS website.
\end{abstract}

\section{Introduction}

Specifically in relation to NPP emergency preparedness and recovery of contaminated areas, many lessons were learned from the way that the Fukushima accident was managed off-site. As pointed out by the IAEA comprehensive Fukushima report (IAEA, 2015), 'the arrangements prior to the accident included criteria for sheltering, evacuation and thyroid blocking in terms of projected dose, but not in terms of measurable quantities'. Criteria for relocation had not been determined, and some evacuated persons ended up being relocated a number of times over less than 24 hours. Also missing were guidelines for the transition from the emergency phase to the recovery phase, where the authorities in Japan eventually decided to build on the current recommendations of the ICRP (IAEA, 2015).

Measurement strategies to support justification and optimization of practical recovery options were lacking, and the first measured quantities were not in-line with needs with respect to optimizing recovery. Since countermeasures could not be selected and implemented quickly, some potentially important recovery options that need early implementation to be effective (Nisbet et al., 2011) were inapplicable. This highlighted the general need for expertise and operational guidelines to provide timely help in selecting suitable countermeasures, and readily available equipment and sufficiently skilled personnel to rapidly carry them out. Particularly, topsoil removal operations resulted in extremely large amounts of often not very highly contaminated soil waste, which pose a great disposal problem (IAEA, 2015). This also highlighted the need for optimizing countermeasure implementation in practice through site-specific assessments. Among other lessons learned with respect to off-site consequences should be mentioned the need to deal with multi-unit and multi-site accidents, primary contaminant releases over potentially as long periods as weeks complicating operation using 'traditional' accident phase planning, and source term characteristics that reflected new types of accident processes, and could perhaps in the future to an increasing extent be predicted through probabilistic safety assessments. On top of everything the accident has led to considerable stigmatization and socio-economic repercussions in the contaminated areas (Hasegawa et al., 2015), the nature and extent of which should hardly surprise in the light of, e.g., the Chernobyl and Goiânia cases 
(Steinhäusler, 2005). Many of these consequences would have been likely to occur at least to some extent also if the accident had happened in any other country, and reflect shortcomings of a generic nature that are important to deal with in building a better and more readily operational preparedness for future accidents.

When addressing lessons learned, they need to be considered in the context of existing management systems and cultures. The Nordic countries have a common cultural and historical heritage that stretches many centuries back, and thus a long tradition of working together to solve societal problems. Specifically with respect to nuclear safety (including emergency preparedness), Nordic cooperation goes back to the 1950's, when the nuclear power concept was first foreseen to promise inexpensive energy based on virtually inexhaustible fuel resources. The long-lasting cooperation has resulted in a common Nordic understanding of things like rules, practices and measures, although national differences exist. Through cooperative initiatives, these comparatively small nations have built, and over decades further developed and refined, a nuclear safety network through which they can together tackle existing and emerging problems more efficiently, more consistently and at a lower cost. In this network, the non-profit organization NKS (acronym for 'Nordisk KerneSikkerhedsforskning' - or in English: 'Nordic Nuclear Safety Research'), holds a central position. It emerged from a Nordic wish to together closely follow the planning and development of nuclear energy systems in the region. NKS is funded by the Nordic countries and has since 1977 run joint Nordic research and development activities (with annual open calls for new project proposals) in the fields of nuclear safety and nuclear/radiological emergency preparedness, addressing the region's specific needs, and ensuring that relevant competence and networking is maintained. For more than 40 years NKS has supported and managed collaborative Nordic research and development projects (Marcus, 1997; Bennerstedt, 2011), and alone since the turn of the century this has produced almost 400 final project reports addressing and describing solutions to various problems identified in Nordic areas or internationally (all freely available on the NKS website www.nks.org), as well as countless peer reviewed journal papers. Another important outcome of this collaboration is building and maintenance of vital networks between the region's key people in the field. To secure future continuity, NKS promotes participation of young scientists in the activities, and also has a dedicated budget for travel support for young scientist competence building.

Since 2011, many NKS projects have specifically targeted on learning points from the Fukushima accident. Currently, the projects are run under two separate programs: the NKS-R (reactor safety) and NKS-B (emergency preparedness - B for 'beredskab' in Nordic language), each with its own program manager. In recent years, NKS has annually co-financed projects with a sum of about 1 MEuro. The participating organisations have at least matched the NKS funding with an own contribution, which has often been given as 'in-kind' payment. Although NKS project budgets are obviously smaller than those often offered by, e.g., the European Commission for their EURATOM research projects, the 'lean' annual project application procedures, uncomplicated project administration and end-user integration as well as efficient size of work groups under NKS shorten the time from conceptual idea to use of a valuable result. This has over the years in many cases enabled NKS projects to reach the first important results and conclusions in relation to emerging international nuclear safety problems. All NKS-B activities have participation from at least 3 different Nordic countries. Non-Nordic participation in NKS activities is possible, but NKS funding of NonNordic organisations is not possible. The project leader must come from a Nordic country (i.e. work for a Nordic organisation). The projects run over one year, but may be prolonged subject to approval of a new application in connection with the next annual call for proposals for new projects.

Also other types of nuclear safety activities are run by NKS. Specifically relating to the Fukushima accident and its implications for nuclear safety, NKS has held two seminars in Stockholm respectively in 2013 and 2016 (each with 100-200 attendants). The first of these sought to describe the immediate new perspectives 
from the Fukushima learning points for Nordic reactor safety and emergency preparedness. The seminar was opened with a session of key note presentations from Tero Varjoranta (general director of STUK), providing an overview of the Fukushima accident and its early lessons, Abel González (then vice chair of ICRP), relating Fukushima lessons to the ICRP system of radiological protection, Wolfgang Weiss (then chair of UNSCEAR), giving related discussions and conclusions from the UNSCEAR project, and André-Claude Lacoste (then president of ASN), who spoke of lessons in relation to needs for further international harmonization from a regulatory perspective. This was followed by sessions discussing learning points for Nordic emergency response, learning points for reactor safety, the way forward with respect to assessments and communication, and the future for Nordic nuclear reactor safety and emergency preparedness. Many participants were inspired by the discussions, resulting in an all-time record breaking number of applications for the next NKS call for project proposals.

The second seminar, in 2016, followed up on this, and among other things reported on the results of some of the many NKS projects run since then to strengthen the capabilities in the Nordic region. Here key note lectures were given by Lyn Bevington (IAEA), who spoke about the then brand new IAEA Fukushima report and its implications for nuclear safety and emergency preparedness. Other key note speakers were this time Chris Clement (Scientific Secretary of ICRP), addressing ICRP experiences from dialogues with Japanese public, nuclear power industry and government, Ted Lazo (Scientific Secretary of OECD-NEA's Committee on Radiation Protection and Public Health - CRPPH), speaking of consequence management lessons from Fukushima, and Tomi Routamo (Deputy Director, STUK), addressing new reactor safety related progress. The other seminar sessions this time covered a mixture of high profile Nordic speakers selected to highlight various important topics to initiate discussion, and reporting and discussions of selected recently conducted NKS project work related to problems highlighted in connection with the Fukushima accident.

All presentations at the two seminars were video filmed, and the video recordings as well as the presentation slides can be seen on the NKS website (respectively www.nks.org/en/seminars/presentations/nks_fukushima_seminar_videos.htm and www.nks.org/en/seminars/presentations/nks-2016-seminar-videos/). Some particularly important concluding views presented were:

- Communication with the public needs to be improved with more use of efficient social media. There is an urgent need for better access to timely, correct and easily understandable information.

- The ICRP system of radiological protection is robust but several issues needing attention have been identified. This includes recognising the importance of psychological consequences and fostering the sharing of information.

- Justification and optimisation are very important when applying countermeasures and remediation. The noble aim of overprotecting the population can backfire and have undesired consequences.

- It could be very difficult for the Nordic countries to cope with a major nuclear accident in Europe.

A third NKS seminar in Stockholm is planned for 2019. This time the scope will be wider, although nuclear emergency preparedness remains a focus topic.

This paper is aimed at providing a contextualised overview of important research and development carried out in the inter-Nordic collaborative program on nuclear emergency management (NKS-B) since the Fukushima accident. For enhanced understanding, the paper also outlines the framework of other pathways of inter-Nordic cooperation in nuclear preparedness. 


\section{Nordic cooperation channels on emergency preparedness}

$N K S$ is as mentioned a key forum for cooperation on emergency preparedness within the Nordic region, focusing on research and development (R\&D) and networking. Over the last 5 years, a total of 48 topical NKS-B projects have been carried out, comprising organization of 23 exercises, workshops or seminars. NKS is jointly owned by five organizations in the Nordic countries, one in each country (Danish Emergency Management Agency (DEMA), Finnish Radiation and Nuclear Safety Authority (STUK), Icelandic Radiation Safety Authority (IRSA), Norwegian Radiation Protection Authority (NRPA), and Swedish Radiation Safety Authority (SSM)).

Also a number of other Nordic organisations, work groups and common work tools play an important role in Nordic emergency preparedness, together with responsible national and local authorities, and these are outlined in the following text to provide a balanced picture of the environment in which the research and development projects are conducted. One of them is the Nordic Emergency Preparedness (NEP) work group, which was established in 1993 by the Nordic nuclear safety and radiation protection authorities for coordination, assistance and exchange of information between Nordic authorities in emergency preparedness and response. The NEP group consists of representatives from all the relevant Nordic authorities, and physically meets twice a year. Some of its specific tasks are to follow and cooperate in the implementation of Nordic and international policies and guidelines in Nordic countries, review and regularly test use of communication tools for emergency situations, carry out tasks approved by the chiefs of the relevant Nordic authorities, and follow up on initialized and finalized Nordic projects. An example of the latter involving NKS was in 2014, when the NKS NordEx 12 and EmSem projects (Pálsson et al., 2014) had been run to extract and describe important findings from a series of recent large scale emergency preparedness exercises held in different Nordic countries (these often have participation from several Nordic countries), and share the experiences in a Nordic project group. Here the NEP group took over the responsibility for organization of sharing and securing integration of lessons learned in Nordic national preparedness, as well as developing follow-up exercise work plans to be considered in the individual authority organisations. Parts of planning and lessons learned from exercises (e.g., when simulating a terror attack or a scenario involving hidden sources) sometimes need to be confidential, and some further integration of project products may not be suitable for inclusion in projects under NKS that has a long tradition for openness in all phases of the work. Here the NEP group can be an important instrument.

The Nordic Public Communication (NPC) group is also a special task group established jointly by the Nordic authorities. The group acts as a forum for exchange of information for Nordic public communication (e.g., information of media interest). Also this group meets twice a year (one of the two meetings is held together with the NEP group). The NPC group regularly discusses cooperation and best practices in nuclear/radiological emergency preparedness. The group has a special email system for rapid communication, which can be used during crises and to coordinate joint aspects of Nordic public communication. A recent discussion issue, also with relation to Fukushima experiences, has been the impact of social media in nuclear/radiological risk communication.

The Nordic cooperation through the NEP and NPC groups is described in brief in the so-called NORMAN manual (2015), which is updated regularly by the NEP group and outlines the framework for operational cooperation between Nordic authorities in response to and preparedness for nuclear and radiological emergencies and incidents. There exist a number of bilateral and multinational agreements on, e.g., mutual assistance and data exchange between Nordic states (also harmonizing Nordic policies with IAEA guidelines). Further, these have all ratified the IAEA conventions on early notification and assistance, and 
Denmark, Finland and Sweden, being EU member states, participate in cooperation on the European Community Urgent Radiological Information Exchange (ECURIE, 2018) system, to which also Norway is party. Denmark, Finland, Iceland, Norway and Sweden all participate in the European Radiological Data Exchange Platform (EURDEP, 2018). To facilitate inter-Nordic cooperation on operational issues, common Nordic guidelines and recommendations for protective actions during early and intermediate phases of nuclear or radiological emergencies have been laid out in a guidebook: the Nordic 'Flag Book' formulated jointly by the Nordic Nuclear Emergency Management and Radiological Protection Authorities (2014).

All the Nordic countries are members of HERCA (Heads of the European Radiological Protection Competent Authorities), which is a voluntary international association established in 2007 to enhance exchange of knowledge and experiences to facilitate practical and harmonized solutions to important regulatory issues in radiation protection. A top priority of HERCA (2018) is to seek harmonization approaches on emergency preparedness and response issues in Europe. HERCA was in the period 20122018 chaired by the head of the Icelandic Radiation Safety Authority, who is also the current chair of NKS since 2006.

A requirement of considerable importance in nuclear/radiological emergency preparedness is adequate predictability of areas affected by high levels of radiocontaminants dispersed through the atmosphere. Since 2001, the Nordic national meteorological services have cooperated under the NORDMET umbrella in areas including observation, information management, product development, training and education. To further facilitate cooperation between members of NORDMET, the MetNet (2017) work group has been established. MetNet actually started as a 3-year NKS-B project (2002-2005), for discussing meteorology issues between Nordic experts and authorities and developing a back-up system enabling all Nordic countries to view model results from all Nordic meteorological services. Today it is established as a specialized permanent Nordic forum for exchange of information and ideas on scientific and operational issues involving emergency preparedness and atmospheric contaminant dispersion. Among other things the group performs real-time exercises on atmospheric dispersion of radioactive matter. It maintains liaison with relevant international activities, including the EU ENSEMBLE platform (Galmarini et al., 2012) that can collect dispersion forecasts provided by more than 20 operational models.

On the research and development level, Nordic organisations naturally also participate in wider international networks in European collaborative research and development projects, particularly under the EURATOM framework. Much focus has here been on the continuous parallel development of the NPP accident management decision support systems, ARGOS (2018) and RODOS (2018). The Danish ARGOS system is operational in Denmark, Norway and Sweden, whereas Finland uses the European RODOS system. Some funding resources in the individual Nordic countries have also supported joint Nordic activities on emergency preparedness. Nordic organisations have further participated in nuclear emergency preparedness competence building networks under the IAEA (e.g., EMRAS, MODARIA).

Finally, the Nordic Society for Radiation Protection (NSFS, 2018) was formed in 1964 as a forum for exchange of knowledge and experience in radiation protection. NSFS is an IRPA Associated Society for the Nordic region and maintains contact with other regional and international societies with similar goals keeping members informed of relevant activities. Notably, NSFS arranges a conference with open call for presentations every 3-4 year. The latest was in Roskilde, Denmark, in 2015, and had more than 100 participants. 


\section{Nordic collaboration on emergency preparedness R\&D activities since the Fukushima accident}

The most important NKS-B projects of this nature can generally be separated into three different categories: early consequence prediction, data assessments, and optimized recovery. It should be noted that in addition to nuclear emergency preparedness, the NKS-B program also runs projects dealing with topics as diverse as potential malicious uses of radioactive substances, disposal of radioactive sources, waste and discharges from decommissioning activities, and management of NORM waste from uranium mining and milling.

\subsection{Early prediction of likely radiological consequences}

Early prediction of dispersion trajectories and deposition of a release of contaminants to the environment can be of high importance in rapidly identifying and categorizing areas with different importance/need of introducing emergency phase countermeasures. In the event of an airborne release, the 'Flag Book' (2014) mentioned above sets commonly agreed Nordic operational intervention levels for implementation of early protective measures for the public including sheltering indoors, iodine prophylaxis, evacuation, and access control, on the basis of assessments or predictions of external dose rates, and/or air concentrations of radionuclides. In the earliest phases of an accidental nuclear release, applicable measurements will often be exceedingly sparse. If possible it may be advantageous to make important decisions already prior to arrival of the plume, and good prediction models are thus crucial. This is also the case for the purpose of emergency preparedness learning, dimensioning, training and drilling, where a representatively wide range of diverse realistic scenarios should be run to provide adequate insight into the associated expectable consequences, so that covering contingency plans may be made operational in time before an actual contaminating event.

The importance of this was highlighted on the basis of the Fukushima case by Gering (2014), who demonstrated some possible adverse implications of operating according to rigid early action frameworks only, when occurrences take a so far unforeseen direction. For instance, if the unusually long lasting contaminant release source term from Fukushima were transposed to a release from a German reactor, the standard dose integration period of 7 days, as defined for comparison with reference levels in Germany, would be much too short, and the sizes of areas in which reference levels for measures like sheltering, evacuation and iodine prophylaxis would be exceeded were shown to be much greater than those relating to standard emergency management planning recommendations. Gering presented his study at the $2^{\text {nd }}$ of the NKS Fukushima seminars, and his presentation can be viewed at http://www.nks.org/en/seminars/presentations/nks-2016-seminar-videos/florian-gering.htm.

The perspective of long lasting releases also introduces a significant likelihood that more than a single intake of stable iodine could be required in preventing high thyroid doses, which is not normally considered in recommendations. In connection with the Fukushima accident Nordic citizens in Japan were in fact provided with contradictory advice regarding use of iodine prophylaxis, which is debated to potentially be associated with a small health risk (WHO, 2017). In-line with the official Japanese recommendation at the time, most Nordic countries early on recommended their citizens in Japan not to implement the measure. However, Swedish citizens residing within $250 \mathrm{~km}$ of the power plant were rapidly recommended to take the stable iodine tablets provided to them. The reason for this was that the picture painted by the Japanese authorities of the implications of the accident was highly uncertain and incomplete, while the Swedish authorities' (SSM) worst case early predictions indicated that iodine prophylaxis would be justified to a distance of 250 $\mathrm{km}$ from the Fukushima NPP. Presentations from the first NKS Fukushima seminar arguing for respectively 
the Swedish

(http://www.nks.org/en/seminars/presentations/nks_fukushima_seminar_videos/lynn_hubbard.htm) and the Finnish view on the matter

(http://www.nks.org/download/FUKUSHIMA SEMINAR/presentations/aaltonen.pdf) can be viewed from the NKS website.

Concerns regarding the sensitivity of the foundation for early phase decision making to differences in modelling tool concepts and their underlying parameters and assumptions, as well as model operator interpretation, prompted the idea of a Nordic consequence assessment intercomparison exercise, in which the primary participants were emergency prognostic expert modellers from the different national authorities in all Nordic countries. This exercise was conducted as the NKS-B project NORCON in 2014-2015 (Dowdall et al., 2015a). The general idea was to use common starting points for the participants, and compare output parameters commonly used to make decisions regarding consequence management. From this it would be possible to identify areas of potential divergence or disparity. The exercise thus essentially involved a comparison of the impact assessment of prognostic tools for estimation of dispersion and deposition, but also analyses of differences in treatment of environmental contaminant transfer and impact parameters were included. Using the systems which each Nordic country would employ in an actual accident situation, calculations were made for actual weather conditions on two specific days in 2014/2015. For each of two source terms defined and each of eight numerical weather prediction models and four atmospheric dispersion models results were generated for each of a number of simulated release dates. It should be mentioned that both longscale Lagrangian and Gaussian (Bartnicki et al., 2014; Havskov Sørensen et al., 2016) and mesoscale puff (Brandt et al. 1996) dispersion models were employed. These models were made and continuously developed in the Nordic countries, but are also incorporated in the European decision support systems. Although some divergence in endpoints was clearly observed particularly for the later phases, as would be expected with independent complex models and methods, the exercise found that there is little reason to conclude that the different approaches to dispersion/transport/impact modelling could result in radically different appreciations of potential consequences.

A problem is of course that the complex European decision support systems generally employ deterministic modelling methods, although parametric uncertainties can be large. With respect to long-range atmospheric contaminant dispersion, this problem was addressed for the first time in the NKS-B project MUD (Havskov Sørensen et al., 2014). Using a new computer-intensive methodology inherent meteorological uncertainty can now be quantified. Ensemble statistical methods have been developed and applied to numerical weather prediction models to describe these uncertainties. Within the project the Danish dispersion model DERMA and the Norwegian dispersion model EEMEP have for illustration been run for a specific hypothetical release scenario from four different nuclear power plants and with four meteorological scenarios, each involving 25 ensemble members of the DMI ensemble prediction system. As might be expected, the dispersion model results in some cases vary considerably across the ensemble. The methodology from the MUD project was applied to the Fukushima Daiichi accident case in the follow-up project FAUNA (Havskov Sørensen et al., 2016). The latter project also comprised a workshop to assess with end-users how the uncertainties could best be presented with the prediction data. The workshop was held in conjunction with an annual meeting of the ARGOS decision support system user group, and concluded that plots showing probabilities of exceeding a threshold contamination level are easier to understand than plots showing percentiles of contamination or minimum-average-maximum. It was however found that training of emergency response staff would be required to ascertain full understanding of the plots. In a second follow-up project, MESO (Havskov Sørensen et al., 2017), the influence of meteorological conditions on atmospheric dispersion modelling 
results was investigated for shorter (meso) range dispersion out to a distance of around $100 \mathrm{~km}$. The results of this suite of projects have attracted much attention internationally, and recently, the quantification of uncertainties in atmospheric dispersion, as well as in other processes of importance for decision making, has been given top priority in European emergency preparedness research (NERIS SRA, 2018).

Noting that an other major factor of importance for early prediction of airborne contamination is the source term, the ongoing NKS-B AVESOME project

(http://www.nks.org/en/nksb/current_activities/emergency_preparedness/avesome.htm) is developing operational methods for quantitative estimation of uncertainties in atmospheric dispersion modelling resulting from uncertainties in assessments of the release of radionuclides from the given accident as well as their atmospheric dispersion. At the first NKS Fukushima seminar a lack of detail in source term estimation for current European decision support systems was pointed out (http://www.nks.org/en/seminars/presentations/nks_fukushima_seminar_videos/wiktor_frid.htm). It would be advantageous if the radionuclide releases could be directly linked to events at the power plant, which would ensure better correspondence with reality, and also by looking at release processes enable better estimation of physicochemical forms (notably with respect to particle sizes and environmental solubility) of the released contaminants. The latter could play a major role for the radiological consequences of the release (Andersson, 2016). It would thus be valuable to enable definition of a range of potential source terms, each with an associated probability, on the basis of assessments of occurrences and reactions made at the power plant. This type of methodology is consistent with the principles of Level 2 PSA (probabilistic safety assessment), which addresses the reactor containment system and phenomenological responses with the objective of determining containment release frequencies for different core damage accident scenarios (Nusbaumer, 2018). Indeed, one of the two release scenario source terms applied in the modelling studies of the NKS-B project NORCON described above was based on a Level 2 PSA study made in 2011 for the Ringhals nuclear power plant in Sweden. NKS also runs projects dealing with the identification of the offsite consequences of nuclear power plant releases on the background of probabilistic safety assessments (Level 3 PSA based on Level 2 analysis). An ongoing NKS project, simply with the title L3PSA, is aimed at increasing the understanding in the Nordic countries of the potential for Level 3 PSA in estimating off-site consequences (including the effects of emergency response options) in a nuclear power plant accident scenario (Olsson et al., 2017). The overall objective of this project is to produce a generic Nordic Level 3 PSA guidance document. The project runs under the NKS-R heading, as many of the key people are reactor experts, and PSA is required in the nuclear industry for risk analysis. Nevertheless, it is a good example demonstrating that power plant experts and emergency management experts can both benefit from collaboration.

\subsection{Data requirements and measurements}

Even in periods with no contaminating incidents it is important to acknowledge that there is a constant need for new data to improve on our understanding of the behaviour of radionuclides released to the environment and their consequences. Only by refining the background for making the crucial assessments can we reduce uncertainties associated with predictions (and at the same time maintain a critical expertise level). Keeping in mind that many of the European state-of-the-art modelling tools are currently still of a deterministic nature, there is a need to assess as well as possible the potential importance of scenario-specific parameters, e.g., in radioecological studies. The NKS-B project PARDNOR (Nielsen and Andersson, 2011), aimed at improving parameters used in the ECOSYS foodchain model (Müller \& Pröhl, 1993), which is an integral 
part of the ARGOS and RODOS decision support systems. A review revealed that a number of parameters (defining anything from deposition to weathering and uptake) in ECOSYS did not reflect the current stage of knowledge, whereas others did not adequately reflect Nordic conditions (e.g., wrt. plant growth, animal feeding regimes, agricultural production and consumer habits). The PARDNOR project, which ran over four consecutive years, collected new data to enable reliable use of ECOSYS for scenarios involving Nordic food production areas. The data has been made freely available to the international decision support system user communities.

In the early phase following a release event, important data would become available, e.g., through networks of permanent monitoring stations, but much may also be learned by measuring contamination levels close to the point of release. Such measurements could however place personnel at unpredictable health risks, and the IAEA thus promoted the use of drones to measure and scan radiation levels around the Fukushima reactors. The potential usefulness of drone measurement techniques (also for, e.g., rapid search for lost sources and in connection with radiological terrorist attacks) has been acknowledged also in the Nordic countries, where the NKS-B project SEMUNARS (Gårdestig et al., 2015) arranged a seminar to reveal the status of unmanned mobile measurement capacities and expectances in the Nordic countries and suggest a common way forward. In the subsequent NKS-B NORDUM exercise (Tazmini et al., 2016) emergency organisations and associated experts from the different Nordic countries demonstrated their different (mostly multicopter platform based) drone approaches in situ to locate and quantify various sources hidden in a forested landscape. The exercise was informative in showing the performances of different carrier platforms and detectors and software. An further follow-up project, NKS-B NEXUS, among other things expanded the challenges to urban environments (http://www.nks.org/en/nksb/current_activities/emergency_preparedness/nexus.htm).

Also carborne measurements can - as evidenced in connection with the events at Fukushima - be a useful and comparatively rapid means for radiological mapping of a contaminated area. The NKS-B project MOBELRAD (Dowdall et al., 2014) provided a unique in situ testing ground in highly contaminated areas of the Belarussian Chernobyl exclusion zone. A wide range of different types of instrumentation were employed by the participating teams, measuring both contamination and dose rate levels. The exercise gave important practical field work experience, and demonstrated how Nordic measurement teams might help each other in a national or regional crisis situation. It also gave very useful 'take home' lessons on the need for maintaining and further developing operational measurement capacities. An important learning point was that the contamination may be highly inhomogeneous, and the measurement signal may thus change rapidly when going by car. It was also found that the role of the instrument operator in interpreting instrument response to variations in environment is complex, and needs to be exercised well to be in place.

The following year, the NKS-B project GAMFAC (Dowdall et al., 2015b) was launched to test Nordic capabilities to conduct in situ gamma spectrometric measurements (not vehicle borne), again as a field exercise in the Belarussian Chernobyl exclusion zone. Applied technologies ranged from small CdZnTe detectors to larger more conventional material detectors including HPGe and $\mathrm{NaI} / \mathrm{LaBr}$ and a wide diversity of software and calibration procedures. It was found that allowing for factors like soil density and carefully selecting optimized models to describe the downward radionuclide migration were important in improving contamination level estimates. As outlined above simple location specific contamination measurements should also be included in the preparations for recovery of any contaminated area. Only by assessing the local distribution of the contamination at some detail is it possible to optimize countermeasure implementation in practice, and secure that agreed 'paper-optimised' strategies do not fail when applied in the field. An other Nordic in situ gamma measurement intercomparison exercise was conducted in Norway 
in the NKS-B NISI project (Gäfvert et al., 2016), to add further to the skills and familiarization with the use of tools for radiological site characterization. The teams reported results that all agreed well both between teams and with the results of a soil sampling carried out in the area 5 years earlier. Such Nordic measurement exercises have been carried out quite regularly for many years to ascertain operational capabilities. On the basic features of gamma spectrometry NKS-B has in recent years almost annually run user workshops/courses, which are always well sought as gamma spectrometry is an important technique for many purposes. The latest of these took place in the autumn of 2017 (Nielsen et al., 2017) and comprised both an intercomparison exercise and a seminar part. Specifically to test Nordic competences for emergency phase identification of radionuclide concentrations using gamma analysis data, a virtual NKS-B exercise was held where participants worked from a series of illustrative spectra (Dowdall et al., 2017).

In assessing the contamination of an area after a major nuclear power plant accident, it should be kept in mind that not all potentially important radionuclides can be measured with gamma spectrometric or dose rate equipment. After the Chernobyl accident, for example, radiocaesium levels were frequently reported, but local levels of pure beta emitters like ${ }^{90} \mathrm{Sr} /{ }^{90} \mathrm{Y}$ were often ignored, simply as they were exceedingly more difficult to measure. Also in the context of radiological dispersal scenarios involving 'dirty bombs' or other aerosolisation devices, some of the radionuclides of primary concern are pure alpha or beta emitters. NKS-B has run projects to look into and expand the Nordic capabilities to measure such radionuclides quantitatively. With automated radiochemistry techniques the response time can be reduced considerably as assessed in the NKS-B project RAPID-TECH (Qiao et al., 2016). Inductively Coupled Plasma (ICP) techniques may also be advantageous in some cases for measuring radiocontaminant levels. A seminar was held in 2017 (NKS-B NORDIC ICP) to discuss further Nordic development and exploration of such methods, which are used by a range of Nordic organisations (http://www.nks.org/en/seminars/upcoming_seminars/nks-b-nordic-icp.htm). On the basis of an intercomparison exercise within the project of ICP-MS measurements it was concluded that while there is a great need for ICP-MS techniques for determination of radionuclides within the Nordic area, there seems to be a knowledge gap between workers in the two most important fields in this context: the radiochemistry and mass spectrometry experts.

A separate early measurement need pertains to radioiodine doses to the human thyroid. Earlier NKS-B intercomparison exercises addressing this need have shown a large variation in dose estimates. Therefore a seminar course about internal dosimetry estimation, focusing on the Public Health England dose model program IMBA was held in the NKS-B project IDEA for interested personnel both from emergency preparedness organisations, hospitals and other (Àrnason et al., 2016). The Nordic countries also collaborate through NKS on assessment of whole body doses to humans (Norrlid, 2011), and has its own library of physical phantoms that can be borrowed by different Nordic organisations through the NKS website (http://www.nks.org/en/phantom_library/) .

\subsection{Optimised recovery and communication}

Good prognostic modelling tools are also needed in optimization of intervention in the longer term (recovery) period after an accidental contamination of land areas. According to the latest ICRP publications (ICRP, 2007; ICRP, 2009), for instance the term residual dose after intervention (projected over the years to come) is an important optimization parameter. With modern decision support systems like ARGOS and RODOS, it is possible to keep track of different population dose rates and estimate accumulated doses and model the effect of countermeasure implementation on different surfaces/objects at different times, which is 
a helpful instrument in finding ideal solutions to contamination problems on different scales. Emergency management research and development of decision support systems should thus go hand in hand, as has also been the case in a number of NKS-B R\&D projects, where for instance the ARGOS modellers/coders have participated directly (see, e.g., http://www.nks.org/en/nksb/current activities/emergency preparedness/avesome.htm).

In the recovery phase optimization process, also other factors like worker doses, direct intervention costs including waste management, wider socio-economic issues, compensation issues, recovery of business, psychological impacts, and ethics are part of the decision matrix. Such factors are treated in a generic sense in the European handbooks for assisting in the management of contaminated areas, which also contain a decision guidance framework of diagrams and tables to visualise implications of countermeasure introduction under different conditions, mainly to assist in exclusion of unsuited methods for specific scenario cases (Nisbet et al., 2011). These handbooks, which deal with different types of areas (including food production, natural and inhabited areas) have to varying extent been implemented in emergency preparedness plans in many European countries, including Nordic areas. They would certainly have been valuable early on after the Fukushima accident, as many of the first countermeasures in Japan were implemented on a 'hit and miss' basis rather than on the basis of existing experience. The core of each European handbook is a series of descriptions of potentially applicable countermeasures for different contaminated surfaces/objects in each type of environment in a standard template facilitating overview and comparison of different method features. This has a few years back been supplied to the Japanese authorities, who have also on the basis of their own experience made similar compendia of countermeasure descriptions (Nakayama et al., 2014). Particularly the European countermeasure template compendium for recovery of inhabited areas is essentially a much further elaboration and expansion of earlier NKS work. The first ever compendium of countermeasure descriptions distinguishing between countermeasure use in different types of contaminated urban areas was published under the NKS project EKO-5 together with short generic text sections on things like dose estimation and formation of strategies based on the template information (Andersson, 1996). Much of the practical background work including knowledge of countermeasure specific features and parameters came from a series of field investigations made by Nordic workers in areas of the former Soviet Union and Sweden contaminated by the Chernobyl accident (Roed et al., 1995). NKS also published a Nordic decision support handbook for recovery of contaminated inhabited areas 3 years before the corresponding, more comprehensive European handbook came out (Andersson et al., 2008). When they were published in 2011, the European recovery handbooks could be considered state-of-the-art, but a number of findings, particularly from the Fukushima accident management, should now be integrated, both with respect to new promising countermeasure methods and to better secure that selected strategies can actually be implemented in practice with the expected effect (e.g., outlining dedicated measurement strategies to optimise practical implementation).

One aspect that is important in maintaining an operational recovery preparedness is field exercising of different aspects from measurement strategies to countermeasure implementation. A fairly new NKS-B report gives an overview of the Nordic exercises held over the first few years after the Fukushima accident (Pálsson et al., 2014). Some of the exercises were originated and arranged by authorities in single Nordic countries, where other Nordic countries were invited to participate. The DEMOEX exercise (Pálsson et al., 2014) comprised a full scale decontamination of a house and the surrounding garden area, which had for the purpose of the experiment been contaminated with ${ }^{99 \mathrm{~m}} \mathrm{Tc}$ in a watery haze. This exercise was carried out in full protective suits with masks, and track was kept of use of consumables and operation time.

However, recovery countermeasure strategies not only need to be operational, but also acceptable to those affected by them. In 2000, NKS published a guide to countermeasures for implementation in the event of a 
nuclear accident that affected Nordic food-producing areas (Andersson et al., 2000). Also here the key content was a series of countermeasure descriptions in standardised templates. In connection with a subsequent NKS exercise (Lauritzen, 2001) a survey was made of which of these countermeasures would be deemed relevant, practicable and acceptable in each Nordic country. Out of a total of 37 methods, general Nordic consensus on these 3 criteria was only found for 4 of the methods, indicating that there could be a need for substantial stakeholder consultation in identifying compromise solutions in terms of suitable recovery countermeasure strategies in the event of an actual contamination situation. In the NKS-B project FOOD, Nordic authorities, experts and stakeholders formed a network and collaborated to identify means for selecting recovery strategies for contaminated food producing systems (Eikelmann, 2011). Also a number of other recent NKS projects have contained elements of stakeholder interaction and public communication. For example the NKS-B PUBPLUME project (Dyve and Hoe, 2014) aimed at making guidelines for presenting the predicted effects of an airborne contamination event in a format that would be quick and easy for the public to understand.

The Fukushima accident demonstrated that also the oceans may become contaminated following a large nuclear power plant accident. The overall goal of the NKS-B project EFMARE (Iosjpe et al., 2016) was to analyse the consequences of radioactive releases to the marine environment. Bioaccumulation processes were modelled and many parametric influences on the consequences, including the season of release, have been studied. Modelling results have been compared with measurements in Nordic water bodies. The results show the need for operational hydrodynamic ocean models in forecasting contaminant dispersal in marine environments. They may for example be important in considering implementation of restrictions related to consumption of seafood.

\section{Conclusions}

A description is given of the various Nordic organisations, working groups and other channels that facilitate Nordic cooperation in the nuclear emergency preparedness area. The Nordic region has a dedicated cooperative research programme and the Fukushima accident has inspired many of the developments in the NKS programme lately. A large number of R\&D projects and other collaborative activities carried out with financial support from the NKS support global needs for development in the field. It is demonstrated that the Nordic R\&D has in a number of cases been at the very forefront of international developments, showing the way forward for further international work. One example is the uncertainty handling in prognostic models, which was highlighted in connection with the Fukushima accident. Here NKS work has resulted in operationally applicable findings specifically in relation to the influences on radiation doses of source term definition and weather predictions. An other example is a comprehensive Nordic study of overall differences in the region's methods for prognostic radiological consequence estimation. Exercising and training is particularly important in maintaining an operational preparedness. Through a coordinated effort, the Nordic countries have sought to obtain maximized experience in this field. Also in, e.g., radioecology and countermeasure optimization, Nordic research groups have contributed greatly to the current state of knowledge that is for instance applied in European nuclear accident management decision support tools. An example of a remaining problem that was seen in both the Fukushima and the Chernobyl case is that current decision tools only go as far as to recommend a countermeasure strategy that is in principle (on paper) optimized. Guidance is needed on strategies, including local in situ sampling/measurements, to secure that practical countermeasure implementation leads to the expected result. Moreover, a great planning effort is needed to ensure that relevant recovery countermeasures can be implemented in time, and the requirements 
in this regard need to be written down in systematic guidelines facilitating the formation of a much more readily operational preparedness. Finally, plans for communication with the public during and after a crisis remain challenging. The many links in this paper to the NKS report base constitute a direct and easily accessible path to further information for all professionals in this field.

\section{References}

Andersson, K.G., 1996. Evaluation of Early Phase Nuclear Accident Clean-up Procedures for Nordic Residential Areas, NKS Report NKS/EKO-5(96)18, Nordic Nuclear Safety Research (NKS), Roskilde, Denmark, ISBN 87-550-2250-2. www.nks.org/en/nks_reports/view_document.htm?id=111010111119565.

Andersson, K.G., Rantavaara, A., Roed, J., Rosén, K., Salbu, B., Skipperud, L., 2000. A guide to countermeasures for implementation in the event of a nuclear accident affecting Nordic food-producing areas, NKS/BOK1.4 project report NKS-16, Nordic Nuclear Safety Research (NKS), Roskilde, Denmark, ISBN 877893-066-9. www.nks.org/en/nks reports/view document.htm?id=111010111119700.

Andersson, K.G., Ammann, M., Backe, S., Rosén, K., 2008. Decision support handbook for recovery of contaminated inhabited areas. NKS report NKS-175, Nordic Nuclear Safety Research (NKS), Roskilde, Denmark, ISBN 978-87-7893-241-9. www.nks.org/en/nks_reports/view_document.htm?id=111010111120097.

Andersson, K.G., 2016. Physico-chemical properties of radionuclides emitted as particulate matter, Radioprotection Vol. 51 (HS2, ISSN 0033-8451), pp. S97-S99.

ARGOS, 2018. PDC-ARGOS CBRN Crisis Management website. , www.pdc-argos.com/.

Árnason, B.B., Brown, J., Norrlid, L.D., Gäfvert, T., Isaksson,M., Nyander Poulsen, A., 2016. Internal Dosimetry Exercise for enhanced Ability, NKS, Roskilde Denmark, ISBN 978-87-7893-439-0. www.nks.org/en/nks_reports/view_document.htm?id=111010213330323.

Bartnicki J., Klein H., Hosseini A., Hov Ø., Haakenstad H., Lind O.C., Salbu B., Szacinski Wendel C.C., 2014. Atmospheric Transport of Radioactive Debris to Norway in Case of a Hypothetical Accident Related to the possible Recovery of K-27 Submarine. MET Report No. 21/3013. Norwegian Meteorological Institute, Oslo, Norway.

Bennerstedt, T.N.O., 2011. Nordic Nuclear Safety research 1994-2008: From standardized 4-year classics to customized R\&B, Nordic Nuclear Safety Research (NKS), Roskilde, Denmark, ISBN 87-7893-323-2, http://www.nks.org/download/pdf/NKS-Pub/NKS-251.pdf.

Brandt, J., Mikkelsen, T., Thykier-Nielsen, S., Zlatev, Z., 1996. The Danish Rimpuff and Eulerian accidental release model (the DREAM), Physics and Chemistry of the Earth, 21 (5-6), pp. 441-444.

Dowdall, M., Behring, J.K., Bondar, Yu, Gudnason, K., Israelson, C., Jónsson, G., Karlsson, S.E., Kock P. K.-J., Möller, B., Møller, P., Nilssen, J., Nilsson, J.M.C., Zbrotski, V., 2014. Mobile measurement: field exercise in fallout mapping in the Belarussian exclusion zone, NKS, Roskilde Denmark, ISBN 978-87-7893400-0. www.nks.org/en/nks_reports/view_document.htm?id=111010212617378. 
Dowdall, M., Dyve, J.E., Hoe,S.C., Blixt Buhr, A.M., Hosseini, A., Brown, J., Jónsson, G., Lindahl, P., Guðmundsson, H., Barsotti, S., Sundell-Bergman, S., 2015a. Nordic Nuclear Accident Consequence Analysis (NORCON): Final Report, NKS, Roskilde Denmark, ISBN 978-87-7893-437-6, www.nks.org/en/nks reports/view document.htm?id=111010213303775.

Dowdall, M., Bondar, Yu, Fristrup, P., Gudnasson, K., Granström, M., Hedman, A., Israelson, C., Jónsson, S., Kjerulf, S., Juul Krogh, S., Mauring, A., Möller, B., Tyler, A., Varley, A., Zabrotski, V., 2015b. Advanced in-situ gamma spectrometry field activity - Chernobyl (GAMFAC), NKS, Roskilde Denmark, ISBN 978-87-7893-436-9, www.nks.org/en/nks_reports/view_document.htm?id=111010213245375.

Dowdall, M., Dyve, J.E., Klein, H., Peltonen, T., Israelson, C., Eriksson, M., Jónsson, G., 2017. Early Phase Source Term Estimation From Gamma Spectra (EPHSOGAM), NKS, Roskilde Denmark, ISBN 978-877893-488-8, www.nks.org/en/nks_reports/view_document.htm?id=111010214694142.

Dyve, J.E., Hoe, S., 2014. Communicating dispersion modelling results to the public, NKS, Roskilde Denmark, ISBN 978-87-7893-389-8, www.nks.org/en/nks reports/view document.htm?id=111010212251410.

ECURIE, 2018. European Community Urgent Radiological Information Exchange, https://rem.jrc.ec.europa.eu/RemWeb/activities/Ecurie.aspx.

Eikelmann, I.M.H., 2011. NKS FOOD Final Report, NKS, Roskilde Denmark, ISBN 978-87-7893-325-6, www.nks.org/en/nks reports/view document.htm?id=111010111126809.

EURDEP, 2018. European Radiological Data Exchange Platform, https://eurdep.jrc.ec.europa.eu/Entry/Default.aspx.

Galmarini, S., Bianconi, R., Appel, W., Solazzo, E., Mosca, S., Grossi, P., Moran, M., Schere, K., Rao, S.T., 2012. ENSEMBLE and AMET: two systems and approaches to a harmonised, simplified and efficient assistance to air quality model developments and evaluation. Atmospheric Environment 53, pp. 51-59.

Gering, F. Gerich, B. Wirth, E., Kirchner, G., 2014. Analysis of the Practicability of External Emergency Planning in Germany based on Experiences from the Fukushima Accident, http://www.irpa.net/members/P09.36.pdf.

Gäfvert, T., Boson, J., Karhunen, T., Jónsson, G., Juul Krogh, S., Drefvelin, J., Hetland, L., Skuterud, L., Reppenhagen Grim, P., Smolander, P., Gudnason, K., Frisk, P., Winther, B., Andreis, C., 2016. Nordic in situ gamma intercomparison. NKS, Roskilde Denmark, ISBN 978-87-7893-462-8. www.nks.org/en/nks reports/view document.htm?id=111010213987456.

Gårdestig, M., Pöllänen, R., Aleksandersen, T.B., 2015. SEMUNARS - seminar on unmanned radiometric systems, NKS, Roskilde Denmark, ISBN 978-87-7893-412-3.

www.nks.org/en/nks reports/view document.htm?id=111010212773251.

Hasegawa, A., Tanigawa, K., Ohtsuru, A., Yabe, H., Maeda, M., Shigemura, J., Ohira, T., Tominaga, T., Akashi, M., Hirohashi, T., Ishikawa, T., Kamiya, K., Shibuya, K., Yamashita, S., Chhem, R.K., 2015. Health effects of radiation and other health problems in the aftermath of nuclear accidents, with an emphasis on Fukushima, The Lancet vol. 386, pp. 479-488. 
Havskov Sørensen, J., Amstrup, B., Feddersen, H., Korsholm, U.S., Bartnicki, J., Klein, H., Wind, P., Lauritzen, B., Hoe, S.C., Israelson, C., Lindgren, J., 2014. Meteorological Uncertainty of atmospheric Dispersion model results (MUD). NKS, Roskilde Denmark, ISBN: 87-7893-385-0.

www.nks.org/en/nks reports/view document.htm?id=111010212220490.

Havskov Sørensen, J., Amstrup, B., Feddersen, H., Bartnicki, J., Klein, H., Simonsen, M., Lauritzen, B., Hoe, S.C., Israelson, C., Lindgren, J., 2016. Fukushima Accident: UNcertainty of Atmospheric dispersion modelling (FAUNA), NKS, Roskilde Denmark, ISBN: 87-7893-444-4.

www.nks.org/en/nks_reports/view_document.htm?id=111010213440189.

Havskov Sørensen, J., Amstrup, B. Bøvith, T., Feddersen, H., Gill, R., Sørensen, M., Vejen, F., Astrup, P., Davis, N., Lauritzen, B., Hoe, S.C., Dyve, J.E., Lindahl, P., 2017. MEteorological uncertainty of ShOrtrange dispersion (MESO), NKS, Roskilde Denmark, ISBN: 87-7893-466-6.

http://www.nks.org/en/nks reports/view document.htm?id=111010214043891.

HERCA, 2018. Heads of the European Radiological Protection Competent Authorities, www.herca.org.

IAEA, 2015. The Fukushima Daiichi Accident, International Atomic Energy Agency, Vienna, ISBN:978-920-107015-9, www-pub.iaea.org/books/IAEABooks/10962/The-Fukushima-Daiichi-Accident.

ICRP, 2007. The 2007 Recommendations of the International Commission on Radiological Protection. ICRP Publication 103. Ann. ICRP 37 (2-4).

ICRP, 2009. Application of the Commission's Recommendations to the Protection of People Living in Longterm Contaminated Areas After a Nuclear Accident or a Radiation Emergency. ICRP Publication 111. Ann. ICRP 39 (3).

Iosjpe, M., Isaksson, M., Joensen, H.P., Jonsson, G., Logemann, K., Roos, P., Suolanen, V., Thomas, R. 2016. Effects of dynamic behaviour of Nordic marine environment to radioecological assessments NKS, Roskilde Denmark, ISBN: 87-7893-442-0.

www.nks.org/en/nks_reports/view_document.htm?id=111010213400466.

Lauritzen, B., 2001. Huginn- a late-phase nuclear emergency exercise, NKS, Roskilde Denmark, ISBN: 877893-073-1. www.nks.org/en/nks_reports/view_document.htm?id=111010111119725.

Marcus, F.R., 1997. Half-a century of Nordic nuclear co-operation - An insider's recollections, NKS, Roskilde Denmark, ISBN: 87-7893-018-9, http://www.nks.org/download/pdf/NKS-Pub/Historiecomplete.pdf

MetNet, 2017. The MetNet Nordic Network of Meteorological Services Engaged in Nuclear Emergency Preparedness, http://metnet.dmi.dk.

Müller, H., Pröhl, G., 1993. ECOSYS-87: a dynamic model for assessing radiological consequences of nuclear accidents. Health Physics 64(3), pp. 232-252.

Nakayama, S., Kawase, K., Hardie, S., Yashio, S., 2014. Remediation of contaminated areas in the aftermath of the accident at Fukushima Daiichi Nuclear Power Station: Overview, analysis and lessons learned - Part 1: A report on the decontamination pilot project, Japan Atomic Energy Authority, JAEAReview 2014-051. 
NERIS SRA, 2018. NERIS - European Platform on Preparedness for Nuclear and Radiological Emergency Response and Recovery. Strategic Research Agenda. www.eu-neris.net.

Nielsen, S.P., Andersson, K.G. (eds.), 2011. PardNor - PARameters for ingestion Dose models for NORdic areas. Status report for the NKS-B activity 2010. NKS, Roskilde, Denmark, ISBN 978-87-7893-304-1. http://www.nks.org/en/nks_reports/view_document.htm?id=111010111120232.

Nielsen, S.P., Rand, A., Bjerk, T., Ramebäck, H, Pöllänen, R., Jónsson, G., 2017. GammaSpec 2017 Proceedings, NKS, Roskilde Denmark, ISBN 978-87-7893-486-4.

http://www.nks.org/en/nks_reports/view_document.htm?id=111010214694094.

Nisbet, A.F., Brown, J., Rochford, H., Cabianca, T., Jones, A., Andersson, K., Duranova, T., Hänninen, R., Ikäheimonen, T., Kirchner, G., Bertsch, V., Gallay, F., Reales, N., 2011. Generic handbook for assisting in the management of contaminated inhabited areas in Europe following a radiological emergency, Version 2, Final report of the EC-EURANOS project activity CAT1RTD02 and CAT1RTD04, published on CEC CD No. EUR 24457, Commission of the European Communities, Luxembourg. www.euneris.net/index.php/library/handbooks.html.

Nordic Flagbook, 2014. Protective measures in early and intermediate phases of a nuclear or radiological emergency: Nordic guidelines and recommendations, Joint report of the Nordic Radiation Protection Authorities,

www.stralsakerhetsmyndigheten.se/Global/Pressmeddelanden/2014/Nordic\%20Flagbook\%20February\%202 014.pdf.

NORMAN manual, 2015. The Nordic Manual (NORMAN): Co-operation between the Nordic Authorities in Response to and Preparedness for Nuclear and Radiological Emergencies and Incidents, Joint report of the Nordic Radiation Protection Authorities, www.stuk.fi/documents/12547/103518/norman-august2015.pdf/f434567b-8ffb-48ac-b8fb-b72cccd94833.

Norrlid, L.D., Halldórsson, Ó., Holm, S., Huikari, S., Isaksson, M., Lind, B., Roed, H., 2011. In-vivo whole body measurement of intern radioactivity in the Nordic countries, NKS, Roskilde Denmark, ISBN 978-877893-310-2. www.nks.org/en/nks reports/view document.htm?id=111010111120246.

NSFS, 2018. Nordic Society for Radiation Protection. http://nsfs.org/?lang=en.

Nusbaumer, O., 2018. Introduction to Probabilistic Safety Assessments (PSA), Free access teaching document, Leibstadt NPP

http://nusbaumer.tripod.com/resources/publications/nusbaumer_introduction_to_probabilistic_safety_assess ments.pdf.

Olsson, A., Caldwell, A.W., Johanson, G., Holmberg, J.-E., Karanta, I., Fritioff, K., 2017. Risk analysis and probabilistic methods, NKS, Roskilde Denmark, ISBN 978-87-7893-472-7.

www.nks.org/en/nks_reports/view_document.htm?id=111010214196737.

Pálsson, S.E. (editor), Hubbard, L., Finck, R., Östlund, K., Selnæs, Ø.G., Aaltonen, H., Breddam, K., Reppenhagen Grim, P., Hansen, M.H., 2014. Nordic sharing of experience from radiation emergency preparedness exercises, NKS, Roskilde Denmark, ISBN 978-87-7893-373-7.

www.nks.org/en/nks reports/view document.htm?id=111010112030909. 
Qiao, J., Salminen-Paatero, S., Holmgren, S., Bourgeaux-Goget, M., Roos, P., Lagerkvist, P., Strålberg, E., 2016. An Inter-comparison Exercise on Evaluating the Application of Novel Techniques in Radiochemical Analysis, NKS, Roskilde Denmark, ISBN 978-87-7893-453-6.

www.nks.org/en/nks reports/view document.htm?id=111010213657179.

RODOS, 2018. RODOS web site: Realtime Online Decision Support System for nuclear emergency management, https://resy5.iket.kit.edu/RODOS/.

Roed, J., Andersson, K.G., Prip, H. (eds.), 1995. Practical Means for Decontamination 9 Years after a Nuclear Accident, Risoe-R-828(EN), Risoe National Laboratory, Roskilde, Denmark, ISBN 87-550-2080-1, ISSN 0106-2840.

Steinhäusler, F., 2005. Chernobyl and Goiânia lessons for responding to radiological terrorism, Health Physics 89(5), 566-574.

Tazmini, K., Robøle, D., Drefvelin, J., Selnes, Ø.G., Vöge Jensen, J., Gårdestig, M., Kettunen, M., Röning, J., 2016. Intercomparison of Nordic unmanned aerial monitoring platforms, NKS, Roskilde Denmark, ISBN 978-87-7893-464-2. www.nks.org/en/nks_reports/view_document.htm?id=111010213997978.

WHO, 2017. Iodine thyroid blocking: guidelines for use in planning for and responding to radiological and nuclear emergencies. Geneva: World Health Organization; 2017. ISBN 9789241550185.

www.who.int/ionizing_radiation/pub_meet/iodine-thyroid-blocking/en/. 